\title{
ENSINO DE PORTUGUÊS COMO LÍNGUA ESTRANGEIRA: NOVAS PERSPECTIVAS
}

\author{
TEACHING PORTUGUESE AS A FOREIGN LANGUAGE: NEW PERSPECTIVES
}

\author{
Cláudia Almeida Rodrigues Murta \\ Universidade Federal de Uberlândia \\ Valeska Virgínia Soaers Souza \\ Universidade Federal de Uberlândia
}

\begin{abstract}
RESUMO: No contexto da globalização, as fronteiras das nações mostram-se cada vez mais tênues, especialmente no que se refere à língua. A interação promovida especialmente pelas tecnologias digitais faz com que haja intercâmbio sociocultural entre os povos e assim como línguas estrangeiras se difundem no cotidiano dos brasileiros, como o inglês e o espanhol, o português do Brasil vem ganhando espaço no cenário internacional. Devido a demandas atuais de eventos esportivos e mobilidade estudantil e profissional, é preciso que a Academia reflita sobre o ensino de português como língua estrangeira, no sentido de preparar seus professores para essa realidade, fomentando ações que considerem os alunos estrangeiros como centro do processo de aprendizagem, propondo práticas educativas nas quais eles possam expressar suas culturas e suas identidades através da língua portuguesa do Brasil e conheçam a cultura brasileira sob o olhar de quem convive com o povo brasileiro. Neste trabalho, investigamos a visão de alunos estrangeiros e de professores em formação que trabalham com português como língua estrangeira, suas percepções sobre o que é ensinar e aprender português à luz da abordagem pós-método, da aprendizagem situada e do hibridismo cultural.
\end{abstract}

PALAVRAS-CHAVE: processo de ensino e aprendizagem; português como língua estrangeira; aspectos culturais.

ABSTRACT: In the context of globalization, the boundaries among nations become increasingly thinner, especially in terms of language. The interaction promoted, especially by digital technologies, fosters sociocultural exchanges between peoples, and while foreign languages - such as English and Spanish - are diffused in the daily lives of Brazilians, Brazilian Portuguese has been gaining ground in the international scenario. Due to current demands of sports events and student and professional mobility, it is necessary that the Academy reflects on teaching Portuguese as a foreign language in order to prepare their teachers to this reality by fostering actions that consider foreign students as the center of the process learning, proposing educational practices in which they can express their cultures and identities through Brazilian Portuguese and learn about Brazilian culture from the perspective of those who live among the Brazilian people. In this paper, we investigate the view of foreign students and teacher students who work with Portuguese as a foreign language, their perceptions of what teaching and learning Portuguese means in the light of post-method approaches, situated learning and cultural hybridity.

KEYWORDS: teaching and learning process; Portuguese as a foreign language; cultural aspects. 


\section{Revista do SELL \\ v. $4, n^{\circ} .1$ \\ ISSN: $1983-3873$}

\section{Introdução}

Quando escreveu "A minha pátria é a língua portuguesa" no século passado, o poeta português - Fernando Pessoa - talvez não imaginava um mundo tão plurilíngue. Nesse novo milênio, no contexto da globalização, as fronteiras das pátrias mostram-se cada vez mais tênues, especialmente no que se refere a qual língua, ou melhor, a quais línguas são faladas por um povo. Da mesma forma que outras línguas estrangeiras se difundem no cotidiano dos brasileiros, como o inglês e o espanhol, o português do Brasil variedade da língua portuguesa falada pelos mais de 190 milhões de brasileiros - vem ganhando espaço no cenário internacional.

Entre as causas apontadas para o crescimento do número de falantes de língua portuguesa, está o interesse econômico pelo Brasil, considerado a maior potência da América Latina. Os dois grandes eventos aguardados para os próximos anos - A Copa do Mundo de 2014 e as Olimpíadas de 2016 - somam-se a esse contexto econômico promissor. Só para a Copa do Mundo, há a previsão de que o país receba aproximadamente 600 mil turistas estrangeiros, que poderão demandar preparação linguística para interações na primeira ${ }^{1}$ língua oficial do país - o português.

Outra causa da crescente demanda por aprender o português brasileiro vem da necessidade de alunos e professores estrangeiros que passam temporadas de intercâmbio estudantil ou profissional no Brasil. Mudanças nas dinâmicas institucionais das universidades brasileiras, que incluem seu processo de internacionalização, fomentam não apenas a prática de brasileiros irem ao exterior, mas também a de estrangeiros virem para nosso país. Programas como o "Ciência sem Fronteiras" visam a uma maior competitividade brasileira por meio do intercâmbio e da mobilidade internacional. Para o referido programa, a meta do governo, até 2014, é de selecionar mais de 100 mil estudantes. Isso, possivelmente, produzirá impactos na reciprocidade dos outros países, que enviarão seus estudantes ao Brasil.

Esse contexto nos instigou investigar qual é a realidade do processo de ensino e aprendizagem de português para estrangeiros no interior do estado de Minas Gerais. As perguntas que nortearam a nossa pesquisa foram: Qual a visão do aluno estrangeiro sobre o ensino da língua portuguesa e da cultura brasileira? Esse ensino ajudou a sedimentar ou desmitificar a ideia que tinham do Brasil antes de aqui chegarem? Qual é

\footnotetext{
${ }^{1}$ A segunda língua oficial do país é a Língua Brasileira de Sinais (LIBRAS).
} 


\section{Revista do SELL \\ v. $4, n^{\circ} .1$ \\ ISSN: $1983-3873$}

realidade do profissional de Letras que ensina a língua portuguesa para estrangeiros das mais diferentes nacionalidades, que chegam ao Brasil por meio de intercâmbios estudantis promovidos por instituições públicas e privadas?

Para responder a esses questionamentos, conduzimos uma pesquisa qualitativa a ser apresentada neste texto. Além desta introdução, organizamos este artigo em outras quatro seções. Primeiramente, como fundamentação teórica, apresentamos considerações acerca de ensino de línguas nos contextos de pós-método e de aprendizagem situada, e reflexões sobre hibridismo e tradução cultural no processo de se aprender línguas. Na sequência, informamos os procedimentos metodológicos seguidos das análises. Para concluir, tecemos algumas considerações finais.

\section{Fundamentação teórica}

\subsection{Ensino e aprendizagem de línguas no contexto pós-método}

Concebemos a linguagem como um sistema dinâmico (LARSEN-FREEMAN; CAMERON, 2008), como atividade no mundo e nas relações entre indivíduos, comunidades e o mundo e, concomitantemente, entendemos o processo de ensino e aprendizagem de línguas em sua natureza multifacetada, permeado pela interação dinâmica entre metodologia e contexto.

O uso da linguagem é consoante com o argumento anterior de que a instrução didática cria práticas não planejadas. O conflito decorre do fato de que existe uma diferença entre falar sobre uma prática do lado de fora e falar de dentro dela. Assim, o uso didático da linguagem, e não em si o discurso da prática, cria uma nova prática linguística, que tem uma existência própria. A participação periférica legítima em tal prática linguística é uma forma de aprendizagem [...] (LAVE; WENGER, 1991, p. 107-108).

Essas ações didáticas, dentre as quais incluímos o ensino de língua estrangeira, têm geralmente se embasado em pressupostos teórico-metodológicos. Anthony (1963) propôs um modelo que ainda pode ser utilizado para distinguir entre diferentes graus de abstração e especificidade no que tange às propostas de ensino de línguas. $O$ autor identificou três níveis de organização relacionados à filosofia e aos procedimentos ao se ensinar uma língua e denominou-os de abordagem (especificação de pressupostos e crenças), método (teoria colocada em prática, quando escolhas são feitas sobre 


\section{Revista do SELL \\ v. $4, n^{\circ} .1$ \\ ISSN: $1983-3873$}

competências e habilidades a serem exploradas) e técnica (procedimentos de sala de aula). E ainda, surge mais tarde nesse cenário o termo metodologia (PRABHU, 1990), que deve ser relacionado às ações intuitivas do professor e não ao planejamento teórico que direciona as ações do professor.

Uma reelaboração das definições de Anthony foi proposta por Richards e Rodgers (1986). De acordo com eles, um método é teoricamente relacionado a uma abordagem, é organizacionalmente determinado pelo design, e é colocado em prática por meio de procedimentos (técnicas, práticas e comportamentos). Uma abordagem refere-se a teorias sobre a natureza da língua e da aprendizagem da língua e ela serve como fonte de prática de princípios para se ensinar uma língua. O design inclui os objetivos do método, o conteúdo programático, os tipos de atividades a serem desenvolvidas, e os papéis atribuídos aos estudantes, aos professores e aos materiais instrucionais.

Prabhu (1990) discute a questão apontando três argumentos de que não há um método ideal, ou melhor, para o ensino de línguas. Ele aponta que:

1) Entre diversos métodos, o melhor é aquele que mais se adequa a um contexto de ensino/aprendizagem específico.

2) Todos os métodos têm o seu valor, ou seja, todos são bons e válidos, a princípio.

3) As avaliações feitas sobre os métodos, se são bons ou não, são bastante equivocadas.

Esse estudioso enfatiza que o melhor método é aquele que o professor, a partir de sua percepção pedagógica, em sua atuação em um ambiente real e específico, em interação com seus alunos, na compreensão da qualidade dos resultados avaliados no processo, escolhe para mediar o caminho a ser percorrido pelos aprendizes em prol da aprendizagem.

Kumaravadivelu (2006), nessa mesma linha, critica modelos tripartites que consideraram uma relação hierárquica simples entre todas essas operações relacionadas ao ensino de línguas - abordagem, método e técnica - e defende que é necessário considerar a conexão complexa entre fatores que podem influenciar esse ensino, como demandas sociais, recursos e limitações institucionais, eficácia da instrução e necessidades dos aprendizes. As ideias de pedagogia pós-método de Kumaravadivelu podem ser resumidas visualizando-se um sistema tridimensional que consiste nos seguintes parâmetros pedagógicos: (a) particularidade: o ensino com sentido não pode ser construído sem uma interpretação holística de situações em particular; (b) praticidade: 


\section{Revista do SELL \\ v. $4, n^{\circ} .1$ \\ ISSN: $1983-3873$}

há uma relação intrínseca entre teoria e prática; e (c) possibilidade: a aprendizagem de línguas é permitida e restringida por questões de poder.

Se ensinar na perspectiva pós-método deve levar em consideração que os alunos aprendem dentro do particular, do prático e do possível, podemos resumir que devemos considerar que a aprendizagem é situada e demanda participação cada vez mais central desses alunos. Tal compreensão não significa a solução para os problemas educacionais. Segundo Lave e Wenger (1991, p. 111):

Caminhar rumo a uma participação central na prática envolve não apenas maior dedicação de tempo e esforço mais intenso, maior e mais ampla responsabilidade dentro da comunidade, e tarefas mais difíceis e arriscadas, mas, de maneira mais significativa, um sentimento identitário crescente de ser um participante central.

Isso significa que o aluno deve se sentir envolvido pelo processo de aprender uma língua não materna; deve estar engajado nesse processo. Esse engajamento geralmente não se inicia com a participação central, mas sim com a participação periférica legítima: o aluno observa e aos poucos caminha rumo a essa centralidade. De qualquer forma, engaja-se mesmo na participação periférica e se o contexto contribui para que compreenda a relevância do que está aprendendo, há a tendência de cada vez participar mais. Entretanto, é importante ressaltar que isso não acontece linearmente ou previsivelmente; trata-se de um processo complexo.

Em suma, a partir de uma visão de linguagem, de ensino, e de aprendizagem como sistemas complexos, defendemos que o professor deve basear-se em seu contexto imediato de atuação, sua intuição pedagógica e em suas concepções de prática docente para mediar o processo de aprendizagem de seus alunos em um processo de desenvolvimento, mudança e coadaptação (VAN LIER, 2004; LARSEN-FREEMAN, CAMERON, 2008). Tal postura não deve deixar de fora os aspectos culturais, assunto que abordamos na seção seguinte.

\subsection{Hibridismo e tradução cultural na aprendizagem de língua estrangeira}

O termo hibridismo tem sido empregado em situações de convivência de diferentes culturas, quer pacífica ou violentamente, e nesse texto relacionamos esse termo à situação de aprendizagem e convivência com uma língua estrangeira. Essa ideia de hibridismo não é nova, mas o acirramento do contato entre povos e culturas diferentes, 


\section{Revista do SELL}

v. $4, n^{\circ} .1$

ISSN: $1983-3873$

promovido especialmente pelas tecnologias da comunicação e pelos deslocamentos de pessoas no globo, tem feito com que o tema entre no debate sobre constituição de identidades e produção textual nos últimos tempos. A noção de hibridismo ressurge com força, no interior de estudos pós-coloniais.

Bhabha (2003, p.165) assim define o termo hibridismo:

O hibridismo é uma problemática de representação e de individuação colonial que reverte os efeitos da recusa colonialista, de modo que outros saberes "negados" se infiltrem no discurso dominante e tornem estranha a base de sua autoridade - suas regras de conhecimento.

Para Bhabha, uma das estratégias discursivas do hibridismo é a mímica ou

(...) signo de uma articulação dupla, uma estratégia complexa de reforma, regulação e disciplina que se "apropria" do Outro ao visualizar o poder. (...) signo do inapropriado (...) uma diferença (...) que ordena a função estratégica dominante do poder colonial, intensifica a vigilância e coloca uma ameaça imanente tanto para os saberes "normalizados" quanto para os poderes disciplinares (BHABHA, 2003, p.130).

Assim, ao se apropriar da linguagem, o autor procura enfatizar a construção do significado pela interpretação ligada à subjetividade histórica e cultural do sujeito, negando a falsa ideia de transparência, homogeneidade da língua e considerando a necessidade de contextualizar o momento da enunciação.

Coelho utiliza o termo em uma pesquisa conduzida no contexto brasileiro, esclarecendo-o:

A hibridização refere-se ao modo pelo qual modos culturais ou partes desses modos se separam de seus contextos de origem e se recombinam com outros modos ou partes de modos de outra origem, configurando, no processo, novas práticas. [...] A hibridização não é mero fenômeno de superfície que consiste na mesclagem, por mútua exposição, de modos culturais distintos ou antagônicos. Produz-se de fato, primordialmente, em sua expressão radical, graças à mediação de elementos híbridos (orientados ao mesmo tempo para o racional e o afetivo, o lógico e o alógico, o eidético e o biótipo, o latente e o patente) que, por transdução, constituem os novos sentidos num processo dinâmico e continuado (COELHO, 1997, p. 125-126).

O hibridismo localiza-se no interior, ou no interstício, dos discursos estabelecidos entre colonizador e colonizado.

Não é mais um meio que facilita o entendimento entre os povos, muito menos uma maneira criativa de permitir o surgimento do novo. Agora, 


\section{Revista do SELL \\ v. $4, n^{\circ} .1$ \\ ISSN: $1983-3873$}

segundo ele, o hibridismo representa aquele "desvio" ambivalente do sujeito discriminado em direção ao objeto aterrorizante, exorbitante, da classificação paranóica - um questionamento perturbador das imagens e presenças da autoridade [...] O hibridismo não tem uma tal perspectiva de profundidade ou verdade para oferecer: não é um terceiro termo que resolve a tensão entre duas culturas, ou as duas cenas do livro, em um jogo dialético de "reconhecimento". [...] O hibridismo é uma problemática de representação e de individuação colonial que reverte os efeitos da recusa colonialista, de modo que outros saberes "negados" se infiltrem no discurso dominante e tornem estranha a base de sua autoridade - suas regras de reconhecimento (BHABHA, 2003, p. 165).

Souza (2004) reafirma a importância do conceito de hibridismo em Bhabha com a explicação a seguir:

Como dissemos, essa percepção e essa valorização do hibridismo cultural requerem o reconhecimento do antagonismo que subjaz ao seu dinamismo e à sua heterogeneidade, antagonismo que resulta das diferentes experiências e conjuntos de valores que constituem a heterogeneidade e contribuem para a constante não sedimentação (unsettling) do conceito de cultura. É esse aspecto que torna o hibridismo cultural - com sua justaposição de valores incomensuráveis - algo produtivo, distante do conceito estéril de hibridismo nas ciências biológicas; porém, ao romper com o discurso homogeneizante e modernista da cultura, a cultura enquanto híbrido se torna uma arena antagonística de diversas formas de conflitos e agências culturais (SOUZA, 2004, p. 126).

A hibridização é, nesse sentido, vista de modo positivo, consiste em um tipo de mistura, mescla, que renova a cultura, produzindo "novos sentidos".

Mas a conceituação do termo não é somente positiva. Gruzinski (2001), em 0 Pensamento Mestiço, desenvolve várias das críticas ao conceito e ao processo de hibridismo:

Por trás de seu caráter aproximativo, esse discurso, que vai se banalizando, não é tão neutro, nem tão espontâneo como parece. Nele é possível enxergar a linguagem de identificação das novas elites internacionais, que, desenraizadas, cosmopolitas e ecléticas, apelam para todo tipo de empréstimo às "culturas do mundo". Tal linguagem corresponderia a um fenômeno social e a uma tomada de consciência desses ambientes acostumados a consumir tudo o que o globo thes oferece, e para os quais o híbrido parece estar desbancando o exótico (GRUZINSKI, 2001, p. 40).

Ao tomar esse termo para analisar a condição de aprendiz de uma língua estrangeira, queremos vislumbrar uma situação de confluência, de mestiçagem, de hibridismo, olhando pelo lado positivo que essa mistura pode condicionar, mas com atenção aos meandros que a hegemonia pode criar. Acreditamos que a aprendizagem de 


\section{Revista do SELL \\ v. $4, n^{\circ} .1$ \\ ISSN: $1983-3873$}

língua estrangeira representa, nesse sentido, uma oportunidade de construção de sentidos ressignificada porque deslocada, ocupando um "terceiro espaço" na denominação de Bhabha (2003), transitando entre diferenças, complexidades, o que pode ampliar as representações, procedimentos, valores, sobre o outro e sobre si mesmo. Em um movimento de atribuir novos sentidos ao mundo, um sentido híbrido, porque impregnado da cultura estrangeira e da cultura materna, abre-se a possibilidade de participar ativamente de práticas sociais alternativas, que desnaturalize a naturalidade das verdades culturalmente criadas. Aprender língua estrangeira nessa perspectiva é manterse em "atitude de atenção", é "ler, se lendo", tomando o apontamento de Souza (2004), é estar aberto a novas possibilidades de ler o mundo, de adaptar-se a contextos diferenciados de classe, de gêneros, de culturas, de línguas, é constituir-se discursivamente em línguas diferentes e ser um homem do mundo.

\section{Metodologia}

Optamos por utilizar os pressupostos da pesquisa qualitativa, coletando dados por meio de mais de um tipo de instrumento, visando entender os pontos de vista dos participantes da pesquisa sob múltiplos vieses. Denzin e Lincoln $(2006$, p.16) defendem que a pesquisa qualitativa é um campo de investigação que se caracteriza por "atravessar disciplinas, campos e temas". Para os autores, apesar das definições variarem de acordo com o momento histórico das pesquisas dessa natureza, uma definição que se aproxima é:

[A] pesquisa qualitativa é uma atividade situada que localiza o observador no mundo. Consiste em um conjunto de práticas materiais e interpretativas que dão visibilidade ao mundo. (...) [A] pesquisa qualitativa envolve uma abordagem naturalista, interpretativa, para o mundo, o que significa que seus pesquisadores estudam as coisas em seus cenários naturais, tentando entender, ou interpretar, os fenômenos em termos dos significados que as pessoas a eles conferem (DENZIN; LINCOLN, 2006, p. 17).

Os participantes de nossa pesquisa pertencem a três grupos distintos:

1. alunos do curso de português para estrangeiros oferecido por um instituto de línguas a intercambistas adolescentes vinculados ao Programa de Intercâmbios de Jovens do Rotary Internacional, cujos países de origem são: Holanda, México, Dinamarca, Alemanha, Estados Unidos e Taiwan. 


\section{Revista do SELL \\ v. $4, n^{\circ} .1$ \\ ISSN: $1983-3873$}

2. alunos do curso de português para estrangeiros oferecido por uma universidade pública, provenientes dos seguintes países: França, Uruguai, Argentina, Paraguai, Rússia, Ucrânia e Polônia.

3. alunos da disciplina de Metodologia e Estágio Supervisionado de Português em Diferentes Contextos, no momento da pesquisa licenciandos em Letras em Língua Portuguesa de uma universidade pública, e, atualmente, graduados como professores.

Para coletar dados para nossa pesquisa de campo, aplicamos questionário aos estudantes intercambistas tanto do grupo 1, quanto do grupo 2. Os questionamentos abrangeram o motivo da escolha pelo Brasil como destino do intercâmbio, relatos sobre as aulas de português e sua relação com o cotidiano, além de sugestões de como essas aulas deveriam ser conduzidas.

Aplicamos, ainda, questionários aos professores em formação, indagando-os sobre suas concepções de linguagem, de ensino de línguas materna e estrangeira, bem como de métodos e o que se mostra relevante nesse processo. Pedimos aos participantes que narrassem experiências relacionadas ao ensino de português como língua estrangeira e sua relação com o curso de Letras. Complementamos essa coleta com as observações de estágio.

Nossas análises, apresentadas na próxima seção, pautaram-se na recorrência de padrões que se repetiram nas respostas tanto de professores em formação, quanto de alunos estrangeiros. O modelo de análise adotado foi o chamado por Yin (1994) de explanation-building, que significa que construímos nossas explicações a partir dos dados coletados à luz das teorias que fundamentaram esse estudo.

\section{Análises}

Dividimos nossas análises em duas subseções. Na primeira, apresentamos os resultados relacionados aos questionamentos feitos aos estudantes intercambistas, e na segunda, aos professores em formação. Salientamos que as identidades dos participantes devem ser mantidas em sigilo, por isso não apresentamos seus nomes, trazendo excertos que representaram os padrões recorrentes das respostas. 


\section{Revista do SELL}

v. $4, n^{\circ} .1$

ISSN: $1983-3873$

\subsection{Reflexões a partir das opiniões dos estudantes intercambistas}

Primeiramente, pedimos que os participantes respondessem à seguinte pergunta: "Você escolheu o Brasil como destino de seu intercâmbio? Por que (sim/não)?". Observamos a partir das respostas, dois padrões distintos. Alguns intercambistas apontam que não escolheram o Brasil e vieram para nosso país devido à falta de vagas em outros países que eram sua preferência.

Não. Porque tinha mais vontade de conhecer outros países antes que Brasil.

Por um lado, esse padrão de respostas contradiz nossa primeira impressão de que - Brasil vem ganhando visibilidade no cenário internacional e que isso tem consequentemente atraído estudantes. Por outro lado, podemos perceber que há uma tentativa de ampliação de vagas de mobilidade estudantil, o que garante que mais estrangeiros tenham a oportunidade de conhecer o Brasil.

Um segundo padrão, mais recorrente que o primeiro, é que muitos intercambistas resolvem ter sua experiência de mobilidade no Brasil devido a relatos de outras pessoas que vieram ao Brasil e viveram uma experiência positiva.

Sim, porque eu tenho um amigo que fez intercâmbio no Brasil. E ele falou o que ele fez no Brasil e como foi a vida dele no Brasil, e achei muito legal, por isso eu escolhi o Brasil.

Isso nos mostra uma sobreposição do local ao global, ou seja, por mais que o bom momento pelo qual o país passa tenha colocado o Brasil em evidência globalmente, é das relações locais - de estrangeiros que conhecem o cotidiano brasileiro - que emerge a vontade de vivenciar um intercâmbio em nosso país.

Outro questionamento, "Suas aulas de português contemplaram atividades em que você pode expressar sua cultura e sua identidade através da língua portuguesa? Qual foi a importância disso?", mostrou-nos o interesse dos intercambistas pela cultura brasileira. Algumas respostas que representam o que foi recorrente são:

Não, ninguém expressou sua cultura, mas não acho que é muito importante porque eu quero aula de português para aprender sobre Brasil e português. 


\section{Revista do SELL}

v. $4, n^{\circ} .1$

ISSN: $1983-3873$

Minhas aulas contemplaram essas atividades e achei importante para mostrar para todos as diferenças entre minha cultura e a cultura brasileira.

Nos padrões de respostas, notamos que os alunos têm curiosidade e interesse em conhecer a cultura brasileira, mas, em momentos em que lhes é propiciada a oportunidade de compartilhar sua cultura, se sentiram impelidos a evidenciar diferenças culturais, especialmente na culinária, literatura, música, etc. O hibridismo cultural (BHABHA, 2003) é marcante em salas de aula de línguas estrangeiras. As culturas do estrangeiro e do nativo vão se misturando, e cada um vai agregando valores culturais estranhos aos seus, mas que passam a ser familiares, podendo contribuir para amenizar preconceitos e conflitos.

Uma terceira reflexão pode ser feita no que se refere à aprendizagem situada (LAVE; WENGER, 1991) a partir do questionamento: "Qual foi a relação entre as suas aulas de português e o seu cotidiano no Brasil? Narre alguma atividade da sala de aula em que essa relação não foi muito clara e outra em que a relação foi clara”.

O vocabulário que a gente aprendia na aula podia usar no dia a dia.

Eu gosto que as aulas de português ensinem a coisa que é importante para a vida no Brasil. Tipo, antes, ensinou a coisa sobre comprar coisas. Eu acho que foi muito bom.

A análise das respostas mostra que os alunos valorizam conhecimentos contextualizados, uma aprendizagem que faça sentido em suas vidas. Aulas centradas em componentes gramaticais com atividades metalinguísticas podem se mostrar fora da realidade de uso da língua.

Finalmente, acreditamos que, para a aprendizagem de português por estrangeiros, é importante considerar que o inglês pode surgir como langue passerelle (HUFEISEN; NEUNER, 2004), ou seja, como língua intermediária entre a língua materna dos estudantes e a língua portuguesa. A partir do seguinte questionamento: "Como você acredita que devem ser aulas de português para estrangeiros? Em que medida as suas aulas de português contemplaram suas expectativas?", obtivemos os padrões de resposta: 


\title{
Revista do SELL \\ v. $4, n^{\circ} .1$ \\ ISSN: $1983-3873$
}

\begin{abstract}
Eu acho que as aulas devem ser como minhas foram, no começo em inglês, tratando as coisas mais básicas do cotidiano primeiro - Estou com fome, etc...
\end{abstract}

The class helped me a lot to be better at the language.

Em turmas de alunos iniciantes, as dificuldades de comunicação entre professores de português e muitos alunos estrangeiros podem manifestar-se em língua inglesa, e essa língua serve como uma língua ponte. A língua inglesa como língua global pode servir para veicular os significados relacionando-os à língua portuguesa. Observamos com esses dados a imprevisibilidade do sistema de aprendizagem, como proposto por LarsenFreeman e Cameron (2008), já que vários estudantes recorreram a um terceiro agente uma terceira língua, o inglês - para mediar entre sua língua materna e o português.

\subsection{Reflexões a partir das opiniões dos professores em formação}

A primeira pergunta do questionário endereçado aos professores em formação foi: "Qual a sua concepção de linguagem e ensino de línguas?" Esse questionamento é relevante, pois a concepção de linguagem direciona o ensino de língua, e a ideia de língua como uma entidade autônoma, dissociada da cultura e da vida social, não condiz com uma prática educativa contextualizada e democrática. A língua é uma das manifestações da linguagem, cuja natureza é, ao mesmo tempo, cognitiva e social, que media a uma situação de interação coconstruída pelos sujeitos.

Observamos um padrão de respostas alinhado com uma concepção sociointeracionista de língua e linguagem.

A linguagem se faz pela interação comunicativa mediada pela produção de efeitos de sentido entre interlocutores, em uma dada situação e em um contexto sócio-histórico e ideológico, sendo que os interlocutores são sujeitos que ocupam lugares sociais.

Acredito que tanto a linguagem quanto a língua são fruto de um complexo sistema de comunicação; constituição identitária; e de manifestação humana e cultural onde a linguagem rege a língua que por sua vez é apenas um dos vários elementos que constituem a comunicação humana. 


\section{Revista do SELL \\ v. $4, n^{\circ} .1$ \\ ISSN: $1983-3873$}

Ao analisar as respostas, percebemos que elas expressam a compreensão de língua como atividade social, como forma de interação, a noção de sujeito que se tem é a de uma entidade psicossocial, de um agente de (re)produção social, que ao mesmo tempo condiciona e é condicionado pelo seu tempo, um sujeito histórico, ator/construtor social (KOCH, 2005).

Outro questionamento foi quanto à ideia que possuíam sobre os métodos de ensino de línguas: "Você acredita que exista um método mais eficiente de aprender línguas?" O padrão de respostas que encontramos reforça inicialmente a ideia de que há a crença da necessidade de um método para se aprender línguas, pois os participantes respondem à pergunta afirmativamente.

Sim, aprender através de conteúdos autênticos e interessantes. Que possa aumentar drasticamente vocabulário. Para aprender uma língua precisa expor-se a ela. Muito!

Sim: o da identificação com uma língua. Ao meu ver, uma língua não se aprende por um método mas por um adressamento (Bakhtin - filosofia da linguagem).

Entretanto, a elaboração das respostas nos mostra que os participantes têm uma concepção pós-método (KUMARAVADIVELU, 2006), especialmente no que se refere à particularidade, já que os sentidos são construídos a partir de conteúdos significativos e da identificação com a língua estrangeira, pressupondo uma interpretação holística de situações em particular.

Outra questão foi: "Você acredita que os princípios que norteiam o ensino de língua materna sejam os mesmos de LE?" Em relação a esse questionamento, tivemos dois padrões de respostas. No primeiro, percebemos uma concepção linear de aprendizagem: uma crença de que mecanismos lineares de causa e efeito, de input/output são garantia de aprendizagem.

Com certeza, pois através dos princípios de ensino de língua materna aprendemos totalmente a língua que é exposta a nós. Deste mesmo modo, é possível que se aprenda também outras línguas de modo efetivo e real.

Contudo, o desenvolvimento linguístico é um fenômeno emergente, nas palavras de Van Lier (2004, p. 224), a linguagem é "uma ferramenta de muitos usos e uma 


\section{Revista do SELL \\ v. $4, n^{\circ} .1$ \\ ISSN: $1983-3873$}

componente chave em todas as atividades de construção de sentido humanas". O segundo padrão de respostas parece concordar com tal concepção.

Isso é variável. Alguns acreditam que ensinar língua materna é ensinar apenas gramática da língua materna. Ao meu ver ensinar língua materna está além disso... está em não apenas ensinar, mas conduzir o aluno a viver a língua que o fala.

A aprendizagem, assim, é situada, e a participação cada vez mais central do aprendiz (LAVE; WENGER, 1991), nas vivências do cotidiano, parece contribuir para a aprendizagem da língua estrangeira.

Os questionamentos seguintes relacionavam-se aos aspectos culturais da aprendizagem: "O que você acredita ser mais importante no ensino de língua estrangeira, aspectos gramaticais ou culturais? Você propicia oportunidades para que seus alunos manifestem suas culturas nas aulas de PLE?" As respostas demonstram uma compreensão híbrida do processo de aprendizagem de português como língua estrangeira.

Os dois têm o mesmo peso, pois ao inserir ao ensino os aspectos gramaticais e culturais, é possível além de ensinar a gramática os aspectos socioculturais da língua em questão.

Acho que o que é mais importante no ensino de LE não são nem aspectos culturais, nem gramaticais e sim aspectos sociointeracionais. A gramática e a cultura não devem ser deixadas de lado, mas de que ambiente social é fruto essa cultura e essa gramática? Muitas vezes precisamos estabelecer pontes entre conteúdos (gramática) e ideais culturais com práxis sociais (Paulo Freire) e abrir espaço para que os alunos os sintam, os vivenciem para que assim se adressem à língua em aprendizagem.

Aprender língua estrangeira, na perspectiva de Bhabha (2003), é transitar entre diferenças, complexidade, o que pode ampliar as representações, os procedimentos, valores sobre o outro e sobre si mesmo, em um movimento de atribuir novos sentidos ao mundo, um sentido híbrido, porque impregnado da cultura estrangeira e materna. É estar aberto a novas possibilidades de ler o mundo e adaptar-se a contextos diferenciados de classe, de gênero, de cultura e de línguas. 


\section{Revista do SELL}

v. $4, n^{\circ} .1$

ISSN: $1983-3873$

A próxima pergunta do questionário relacionava-se à contribuição do curso de Letras para o ensino de PLE na formação do professor: "Narre sobre a contribuição que o curso de Letras proporcionou como subsídios teórico-metodológicos para sua atuação como professor de PLE".

Propiciou com a teoria e os métodos ensinados no curso de Letras para o ensino de como ser professor de PLE, norteou embasamento e principalmente o que hoje mais falta ao ensino, que é a teoria aliada à prática.

Foi muito bom, em especial no que diz respeito à metodologia e estágio de PLE. Sendo sincero foi o momento mais interessante da minha graduação, momento este que li coisas novas e não repetidas como fizemos em todas as disciplinas de metodologia de ensino e estágio supervisionado de LE. Além disso, foi o único estágio que produzimos materiais didáticos de ensino de língua fundamentados em pesquisas feitas por nós mesmos. Foi um momento onde demos início ao profissionalismo, coisa que não aconteceu nos outros estágios, onde fizemos exclusivamente resenhas e debatemos textos que não tinham nada a ver com DIDÁTICA.

O padrão de respostas nos mostra que uma formação pautada em uma visão holística, na indissociabilidade entre teoria e prática e na pesquisa em sala de aula, é fundamental para preparar o futuro docente para atuar como professor de língua portuguesa como língua estrangeira. Percebemos, em nossas observações em sala de aula durante a condução da disciplina de Estágio supervisionado em PLE, que o professor é quem tem condições de analisar o contexto de ensino e aprendizagem no qual irá atuar e desempenhar seu papel de articulador de sentidos, que promove a colaboração e agência de seus alunos, por meio de práticas situadas, pela interação e vivência com a língua estrangeira, relacionando aspectos linguísticos e culturais, adaptando e produzindo materiais que façam sentido na aprendizagem dos alunos.

E a última pergunta: "Narre sobre as maiores dificuldades que você enfrenta como professor de PLE". Um dos padrões de respostas nos remete à concepção de metodologia (PRABHU, 1990), de que não há um método ideal, ou melhor, para o ensino de línguas e que entre diversos métodos, o melhor é aquele que mais se adéqua a um contexto ensino/aprendizagem específico. 


\section{Revista do SELL}

v. $4, n^{\circ} .1$

ISSN: $1983-3873$

As maiores dificuldades foram poucas, pois ao ensinar procuro me preparar antes para que as dificuldades reais em sala sejam sanadas. Mas as poucas dificuldades que tive foram em relação ao tempo que é escasso, e respeitar o tempo da aprendizagem de cada aluno que é diferente um do outro.

Podemos notar a preocupação nas palavras do participante de estar atento ao contexto específico de aprendizagem. O segundo padrão evidencia a natureza ideológica das relações culturais e linguísticas, mostrando que os embates ideológicos são marcados nas relações sociais e isso ocorre obviamente na sala de aula de línguas estrangeiras.

Os enfrentamentos e choques culturais ocorridos nas primeiras aulas são os maiores problemas que temos. Os alunos chegam dispostos a nos testar, a validar o nosso conhecimento de mundo, e em especial fazem perguntas sem resposta exata em relação a nossa cultura, e isso tudo muito agressivamente.

Corroboramos a ideia de Gruzinski (2001) de que a hegemonia linguística e cultural marca as relações de poder, o enfrentamento, entre as línguas e culturas. Esse embate pode ser superado ou exacerbado conforme a problematização conduzida pelo professor. O participante indica que esse enfrentamento ocorre mais no início das interações, mas acreditamos que, à medida que a convivência vai se estreitando e, professor e alunos partilhando suas culturas e experiências de vida, pode acontecer a superação desse conflito.

\section{Considerações finais}

No intuito de responder às perguntas norteadoras de nosso estudo, escutamos as vozes de alunos estrangeiros sobre o ensino da língua e da cultura do Brasil, e entendemos algumas questões que eles valorizam para seu processo de aprendizagem. Atividades de ensino para pequenas comunidades de aprendizagem compostas por estrangeiros de diferentes culturas tendem a contribuir para desmitificar estereótipos que esses estudantes trazem consigo, caso essas atividades sejam "situadas", incorporadas ao que está sendo vivenciado no contexto de aprendizagem de português como "segunda" língua. Nosso pressuposto inicial de refletir sobre língua "estrangeira", como 


\section{Revista do SELL}

v. $4, n^{\circ} .1$

ISSN: $1983-3873$

geralmente encontramos em livros didáticos e em ofertas de cursos no Brasil, precisou ser revisto para entender o contexto de "segunda" língua, no qual há a imersão linguística e cultural dos aprendizes.

Em relação à realidade do professor em formação de Letras que trabalha no contexto de ensinar a língua portuguesa para estrangeiros das mais diferentes nacionalidades, que chegam ao Brasil por meio de intercâmbios estudantis promovidos por instituições públicas e privadas, percebemos que sua vivência teórico-prática contribui para que eles "situem" suas propostas de atividades de ensino que demonstram estar inseridas em uma perspectiva pós-método, que valoriza o contexto em que o trabalho está sendo desenvolvido.

Mesmo sendo uma investigação limitada da percepção de estrangeiros e brasileiros sobre o processo de aprender e ensinar o português, algumas reflexões sobre o contexto atual emergiu desse estudo. Uma dúvida é se o sistema escolar brasileiro, tanto público quanto privado, está preparado para essa demanda. Há ainda poucos materiais didáticos apropriados à realidade de aprendizes oriundos de diferentes regiões do mundo, que trazem consigo sua bagagem cultural, mas que terão que dividir a mesma sala de aula e o mesmo professor. Uma possível solução é fomentar ações que considerem os alunos estrangeiros como centro do processo de aprendizagem, propondo práticas educativas nas quais eles possam expressar suas culturas e suas identidades.

Durante as aulas, os alunos poderiam participar de atividades didáticas aprendendo não apenas sobre a cultura brasileira, mas socializando um pouco da cultura de sua pátria. Haveria uma tentativa, assim, de colocar em prática um provérbio chinês: "Diga-me e eu esquecerei; ensina-me e eu lembrarei; envolva-me e eu aprenderei". São essas pequenas ações embasadas em uma filosofia de ensino inovadora que podem ajudar nosso país a acolher da melhor forma possível os estrangeiros durante sua estadia no Brasil: envolvendo-os no processo de aprendizagem de nossa língua portuguesa.

Lembrando que todo ato educativo é um ato de reflexão crítica, defendemos que aprender a escutar/ouvir e que a produção de significados são construções sociais, culturais, políticas forjadas na coletividade, a partir de um sistema de crenças, valores, interesses. Aprender língua estrangeira nessa perspectiva crítica e situada é manter-se em "atitude de atenção", é "ler, se lendo" (SOUZA, 2004), é estar aberto a novas possibilidades de ler o mundo, de adaptar-se a contextos diferenciados de classe, de gêneros, de culturas, de línguas, é constituir-se discursivamente em línguas diferentes. 


\section{Revista do SELL}

v. $4, n^{\circ} .1$

ISSN: $1983-3873$

\section{Referências:}

ANTHONY, E. Approach, method and technique. English Language Teaching, v. 17, p. 63-57, 1963.

BHABHA, H. K. O local da cultura. Trad. de Myriam Ávila et. al. Belo Horizonte: Editora da UFMG, 2003.

COELHO, T. Culturas híbridas. In: Dicionário crítico de política cultural: cultura e imaginário. São Paulo: Fapesp; lluminuras, 1997.

DENZIN, N. K.; LINCOLN, Y. O planejamento da pesquisa qualitativa: teorias e abordagens. Tradução de Sandra Regina Netz. 2. ed. Porto Alegre: Artmed, 2006. 432 p.

GRUZINSKI, S. O pensamento mestiço. São Paulo: Companhia das Letras, 2001.

HUFEISEN, B.; NEUNER, G. The plurilingualism project: tertiary language learning German after English. Strasbourg: Council of Europe Publishing, 2004.

KOCH, I. G. V. Desvendando os segredos do texto. São Paulo: Cortez, 2005.

KUMARAVADIVELU, B. Understanding language teaching: from method to post-method. New Jersey: Lawrence Erlbaum Associates, 2006.

LARSEN-FREEMAN, D.; CAMERON, L. Complex systems and applied linguistics. Oxford: Oxford University Press, 2008. 287 p.

LAVE; J.; WENGER, E. Situated learning: legitimate peripheral participation. Cambridge: Cambridge University Press, 1991.

PRABHU, N. S. There is no best method - why? Tesol quarterly, v. 24, n. 2, p. 161-176, 1990.

RICHARDS; J. C.; RODGERS, T. Approaches and methods in language teaching. Cambridge: Cambridge University Press, 2000.

SOUZA, L. M. M. Hibridismo e tradução cultural em Bhabha. In: ABDALA JR., Benjamin (Org.). Margens da cultura: mestiçagem, hibridismo e outras misturas. São Paulo: Boitempo, 2004.

VAN LIER, L. The ecology and semiotics of language learning: a sociocultural perspective. Boston: Kluwer Academic Publishers, 2004. 248 p.

YIN, R. Case study research: design and methods. Thousand Oaks, CA: Sage Publishing, 1994. 